\title{
Debatt
}

\section{Praktiknära forskning - en evig fråga?}

Karin Rönnerman, professor em.

Institutionen för pedagogik och specialpedagogik, Göteborgs universitet Kontakt: karin.ronnerman@gu.se

Redaktionen för tidskriften Pedagogisk forskning i Sverige har bjudit in till en nationell debatt över temat Praktiknära forskning - ett paradigmskifte på gång? Ett lovvärt initiativ där det $\mathrm{i}$ inledningen till debatten mycket riktigt anges att detta inte är en ny fråga för pedagogisk forskning i Sverige (Debatt, 2020). Dock har den under de senaste decennierna fått ny aktualitet genom reformer, betänkanden, utredningar, ny myndighet och en försöksverksamhet om modeller för samverkan, ULF. Jag har (tillsammans med andra) blivit inbjuden att kommentera de inlägg som publicerats, vilket jag tackar för.

Förutom den inledande texten finns tio artiklar publicerade. Alla författare ger sin syn på praktiknära forskning som begrepp och på hur den kan utformas utifrån sina specifika forsknings- eller ledningsperspektiv. Inte förvånande lyfts frågan om vad praktiknära forskning är och ska innehålla (Nilholm, 2020; Persson 2020), hur den praktiskt ska genomföras (Hermansson \& Ahnborg, 2020) liksom betydelsen av avtal mellan parter för samverkan och som grund för externa medel (Jarl \& Taube, 2020; von Greiff 2020). Ytterligare inlägg betonar på olika sätt vikten av det lokala sammanhanget (Blossing, 2020; Serder \& Malmström, 2020; Wedin, 2020), samt hur samverkan kan förstås som ett tredje rum (Olsson \& Brunner Cederlund, 2020; Prøitz, 2020). Samtliga bidrag pekar på aspekter som alla är viktiga att ta $\mathrm{i}$ beaktande för att man ska kunna utveckla fältet praktiknära forskning vidare. Såväl avtal som strukturer måste finnas på plats, men om vi inte i högre grad fokuserar på det lokala sammanhanget och på lärares verksamhet gynnar inte forskningen dem den berör, det vill säga professionen och därmed i förlängningen elevernas utveckling och lärande. 
Det är viktigt att lyfta frågan om hur den lokala skolans organisation påverkar lärarnas möjligheter att medverka i ett gemensamt projekt. Det räcker inte med överenskomna och skrivna avtal på olika nivåer i skolsystemet, så länge inte den viktigaste länken innefattas, nämligen lärarnas villkor att medverka $\mathrm{i}$ forskning. Lärarna själva behöver medverka för sin professionella utveckling det vill säga de bör själva vara aktörer. Att medverka i ett projekt innebär ett stort arbete: tid för datainsamling, analys och reflektion samt tid för möten. Tid som vanligtvis inte finns inlagd för lärare som arbetar i skolan. Här skiljer sig förutsättningarna åt mellan forskare och lärare. Medan forskaren genom externa medel har nedsättning i tjänsten och kan planera för sin medverkan i projektet, finns inte denna tid inskriven i den verklighet som läraren verkar inom. Den tiden behövs för att praktiknära forskning ska bli en del av vardagsarbetet och inte ett projekt pålagt utifrån. Min egen erfarenhet i samverkansprojekt är att skolhuvudmän och rektorer ofta är mycket intresserade av att medverka i ett forskningsprojekt där avtal finns på plats. Men, när projektet väl kommer igång visar det sig att lärarna inte alltid har tid avsatt för medverkan eller kan komma ifrån på extra möten. Lärarens situation ser med andra ord annorlunda ut än forskarens. Här visar Olsson och Brunner Cederlund (2020) på en möjlighet för varaktiga mötesplatser. I den försöksverksamhet som bedrivs vid Uppsala universitet organiserar man för forskningsmiljöer gemensamma för huvudmän och lärosäten, något de kallar för ett tredje rum (se även Prøitz, 2020). Här påpekas att ett jämbördigt rum innebär möten för att skapa en gemensam diskurs och gemensamt språk, men att dessa processer tar tid.

Praktiknära forskning i samverkan med forskare måste också visa på en väg att fortsätta arbetet när de avsatta projektmedlen är slut. Här kan aktionsforskning, som det finns närmare hundra års erfarenhet av i utbildnings- och vårdsektorerna, vara en framkomlig väg. Man måste kunna dra lärdom av vad som tidigare skett. Aktionsforskning innebär både ett aktörskap i meningen att driva förändring av praktiken och en forskningsaspekt som avser att skapa kunskap om praktiken. I studier tillsammans med australiska kollegor har vi uppmärksammat aktionsforskningens potential att generera drivkraft för ledning av verksamheten (Edwards-Groves \& Rönnerman, 2013; Edwards-Groves \& Rönnerman, in press). Detta ledarskap har vi benämnt mellanledande och där vi varit noga med att detta inte är en position i ledningsgruppen utan bygger på kollegialitet (Grootenboer, Edwards-Groves \& Rönnerman, 2015, 2020; Rönnerman, Edwards-Groves \& Grootenboer, 2018). En mellanledare är till största delen verksam som undervisande lärare men innehar också ett uppdrag som ledare. Detta uppdrag är inte en speciell tjänst, utan ett åtagande riktat mot att leda kollegornas professionella lärande och verksamhetens utveckling. 
En mellanledare kan enkelt sett placeras i mitten, mellan sina kollegor och mellan kollegorna och rektor i organisationen. Denna position är dock inte enkel eller oproblematisk. Den förutsätter förhandling med både kollegorna och med rektor avseende i första hand tid och rum för kollegiala möten. Genom dessa förhandlingar engagerar sig en mellanledare också oftast samtidigt i a) ledande och undervisande, b) organiserande och handledande c) samarbetande och kommunicerande (Rönnerman m.fl., 2018, s. 26-29; Rönnerman, 2020). När man involverar mellanledare i förhandlingar om praktiknära forskning sätter man verksamheten i fokus. Frågan "vad händer här"? aktualiseras i stället för "vad fungerar här"? som Serder och Malmström (2020) så observant noterat i relation till aktionsforskning och praktiknära forskning. Praktiknära forskning behöver med andra ord "situeras socialt, historiskt och kulturellt" i likhet med vad Wedin (2020) påpekar. På samma sätt betonar Blossing (2020), vikten av det lokala sammanhanget och faran med att inte se de praktiker lärare är involverade i.

Praktiknära forskning handlar alltså inte bara om elevers lärande och undervisning utan inbegriper även övriga praktiker som ledarskap (mellanledare och rektorer), lärares kompetensutveckling, forskning och utvärdering. Det räcker inte att enbart förändra en av dessa praktiker då praktikerna hänger samman och påverkar och påverkas av varandra (Rönnerman m.fl., 2018). För att praktiknära forskning ska leda till förändring behöver lärares medverkan organiseras på lokal nivå. Det är avslutningsvis värt att upprepa Lawrence Stenhouse konstaterande från 1975: "Det räcker inte att lärares arbete studeras, lärare behöver själva studera det egna arbetet" (min översättning).

\section{REFERENSER}

Blossing, Ulf (2020). Samverkansprocessens problematik i den praktiknära forskningen. Pedagogisk Forskning i Sverige. Ahead of print. https://pedagogiskforskning.se/debatt-2020-praktiknara-forskning/

Debatt 2020 Praktiknära forskning - ett paradigmskifte på gång? - en introduktion. Pedagogisk Forskning i Sverige, 25(1), 100-101.

Edwards-Groves, Christine, \& Rönnerman, Karin (2013). Generating leading practices through professional learning. Professional Development in Education, 39(1), 122-140. DOI: $10.1080 / 19415257.2012 .724439$

Edwards-Groves, Christine, \& Rönnerman, Karin (in press). Generative Leadership. Rescripting the promise of action research. Singapore: Springer.

von Greiff, Camilo (2020). Praktiknära forskning - ett område med vind i ryggen! Pedagogisk forskning i Sverige, 25(2-3), 153-156. DOI:

https://doi.org/10.15626/pfs25.0203.08 
Grootenboer, Peter, Edwards-Groves, Christine, \& Rönnerman, Karin (2015).

Leading practice development: voices from the middle. Professional Development in Education, 41(3), 1-19. DOI: 10.1080/19415257.2014.924985

Grootenboer, Peter, Edwards-Groves, Christine, \& Rönnerman, Karin (2020). Middle Leadership in Schools. Leading Professional Learning. London/New York: Routledge. DOI: 10.4324/9781003026389

Hermansson, Karin, \& Ahnborg, Marie-Hélène (2020). Praktiknära forskning i samverkan - hur ska det gå till? Pedagogisk forskning i Sverige, Ahead of print. https://pedagogiskforskning.se/debatt-2020-praktiknara-forskning

Jarl, Maria, \& Taube, Magdalena (2020). Organiserade partnerskap i lärarutbildning lägger grund för praktiknära forskning. Pedagogisk forskning i Sverige, Ahead of print. https://pedagogiskforskning.se/debatt-2020-praktiknara-forskning

Nilholm, Claes (2020). Praktiknära eller uppdragsrelevant forskning? Pedagogisk forskning i Sverige, 25(2-3), 157-159. DOI: https://doi.org/10.15626/pfs25.0203.09

Olsson, Lars, \& Brunner Cederlund, Anna (2020). Det tredje rummet som mötesplats. Pedagogisk, forskning i Sverige, Ahead of print. https://pedagogiskforskning.se/debatt-2020-praktiknara-forskning.

Persson, Anders (2020). Dubbel närhet och distans behövs inom praktiknära forskning. Pedagogisk forskning i Sverige, 25 (2-3), 149-152. DOI: https://doi.org/10.15626/pfs25.0203.07

Prøitz, Tine, S. (2020). Praksiksnær forskning og partnerskap i et tredje rom. Pedagogisk forskning i Sverige, Ahead of print. https://pedagogiskforskning.se/debatt2020-praktiknara-forskning

Rönnerman, Karin (2020). Organisera skolutveckling med lärare som mellanledare. I Hirsh, Åsa, \& Olin, Anette (red.), Skolutveckling i teori och praktik. Malmö: Gleerups.

Rönnerman, Karin, Edward-Groves, Christine, \& Grootenboer, Peter (2018). Att leda från mitten - lärare driver professionell utveckling. Stockholm: Lärarförlaget.

Serder, Margareta, \& Malmström, Martin (2020). Vad talar vi om när vi talar om praktiknära forskning? Pedagogisk forskning i Sverige, 25(1), 107-109. DOI: $10.15626 / \mathrm{pfs} 25.01 .07$

Stenhouse, Lawrence (1975). An introduction to Curriculum Research and Development, London: Heineman.

Wedin, Åsa (2020). Att hantera mindre goda exempel - dilemma för praktiknära forskning. Pedagogisk Forskning i Sverige, 25(1), 102-105. DOI:

https://doi.org/10.15626/pfs25.01.06 